\title{
How Does Corporate Social Responsibility Promote Innovation? The Sequential Mediating Mechanism of Employees' Meaningfulness of Work and Intrinsic Motivation
}

\author{
Byung-Jik Kim \\ College of Business, KAIST \\ Kimbj82@business.kaist.ac.kr
}

\author{
Young Kyun Chang \\ Sogang University \\ changy@,sogang.ac.kr
}

\author{
Tae-Hyun Kim \\ College of Business, KAIST \\ taehyun@business.kaist.ac.kr
}

\begin{abstract}
Based on group creativity framework, our research investigates how corporate social responsibility (CSR) promotes innovation of firms by revealing sequential mediating mechanisms of employee's meaningfulness of work and intrinsic motivation. By applying a multi-level approach, this study examines the internal processes of micro-level variables between two macro-level variables (i.e., CSR and innovation). Utilizing a 3-wave longitudinal data from 4,178 organizational members in 502 branches as well as objective CSR records from one of the largest Korean commercial banks, we found that employee's meaningfulness of work and intrinsic motivation sequentially mediate the CSR-innovation link. The results suggest that CSR functions as a powerful driver of innovation through enhancing employees' perceptions and attitudes toward their job.
\end{abstract}

\section{Introduction}

Does a firm's social engagement really contribute to innovation of the firms? This question is relevant to the most firms, not only because innovation is an essential capability to survive in today's competitive business environment, but also because a firm's desire to becoming a corporate citizen would be waned unless social engagement contributes to the innovation. In this paper, we assume that corporate social responsibility (CSR) serves as a trigger of corporate innovation.

CSR has received great attention from scholars and practitioners in business fields. CSR refers to a company's obligations to contribute to the welfare of various stakeholders, including shareholders, employees, customers, local communities, and environment in the process of managing a business [1]. The positive reputation of CSR originates in its strategic value to strengthen a competitive advantage of the company by enhancing various organizational effectiveness [2, 3], such as a firm's reputation [4], a consumer's evaluation of the company and its products [5], financial performance [6, 7], attractiveness to investors [8], and organizational commitment [9].

Although many scholars have examined the relationship between CSR and various organizational outcomes, we believe that there are several issues still to be addressed further. First, despite the accumulated knowledge from the existing literature, the influence of CSR on innovation has received a minimal attention. Given the importance of innovation of the firm for the organizational effectiveness as well as long-term survival $[10,11]$, it is worthwhile to explore the possibility that CSR promotes innovation. While very few studies have focused on the relationship between CSR and employee-level creativity [12], it is still underexplored whether CSR promotes an actual innovation at a firm-level [13].

Second, extant research on the CSR-organizational outcomes link has relatively paid little attention to micro-level underlying mechanisms [2, 14]. Recent studies have pointed out that inconsistent or mixed results for the link (i.e., positive, negative, and nonsignificant) may be due to neglecting important mediating mechanisms through which CSR influences the organizational outcomes [14]. In addition, the previous literature has been predominately externallyoriented. Those studies mainly have focused on the external stakeholders, such as shareholders, customers, and local communities, to describe why CSR promotes organizational outcomes, conducting a macro-level analysis (e.g., organizational- and institutional-level research). In fact, the important role of internal stakeholders, such as employees, to explain the relationship has been relatively underexplored [2, 14]. Given that employees, as a CSR implementer, are the ones who actually translate CSR into the various organizational outcomes $[2,14,15]$, their impacts should be integrated into the relationship. Thus, our attempt to reveal the micro-level underlying mechanism between CSR and organizational innovation would contribute to the current literature. 
In this study, we investigate the sequential mediating role of employees' meaningfulness of work and intrinsic motivation as an underlying mechanism to describe how CSR influences organization-level innovation. By relying on group creativity framework [16] as an overarching framework, this paper attempts to integrate the macro- and micro perspectives into a single comprehensive model. Overall, the group creativity model suggests a theoretical framework that explains how input variables (e.g., group norms, organizational structure and goals, diversity and cohesiveness of group, and group members' personalities and abilities) affect group-level creativity. This frame emphasizes the important role of various intermediating processes (i.e., cognitive, motivational, and social processes) between input factors and creativity [16, 17]. Because CSR activities could be interpreted as both critical group norms and an organizational goal, CSR can be an important input factor. Through CSR practices, employees' common belief about positive social impact of their work would boost their meaningfulness of work (as a cognitive process), and in turn make them experience a deeper intrinsic motivation (as a motivational process). Eventually the enhanced intrinsic motivation of employees would be the source from which innovation of the organization is triggered (as an output factor).

Specifically, we first focus on the important role of meaningfulness of work which translates CSR practices into innovation. Meaning of work has a variety of definitions, ranging from general beliefs, values, and attitudes towards their work [18], to the psychological experience and significance of their work [19]. In an organizational setting, it critically influences how employees interpret various events in their work, what they experience within the organization, and how they conduct their jobs [20,21]. As such, meaningfulness of work is found to be closely related to key attitudes and behaviors of employee, including organizational identification, job satisfaction, employee engagement, well-being, organizational commitment, and organizational citizenship behavior [20-25].

Among various ways to enhance meaningfulness of work, contributing to society would be one of critical means to achieve the goal $[20,26]$. When individuals recognize that they can make others better off and change society for the better place through their work, they can find the meaning of work [19, 26, 27]. Since CSR practices can be an effective way to contribute to society through their work, employees may find meaningfulness of work through the activities [28].

In addition, broaden and build theory [29] provides an insight on the relationship between meaningfulness of work, intrinsic motivation, and innovation. According to the theory, an employee's experience of meaningfulness of work serves as a source of intrinsic motivation [20, 30]. Intrinsic motivation refers to the degree to which an individual is inner-directed to participate in order to experience the activity itself, rather than a means to gain external rewards [31]. Psychological mechanism of the linkage is as follows. Meaningfulness of work enhances a variety of positive perceptions, such as job satisfaction [25], engagement [24], which in turn increase their positive emotions [31]. The positive emotions, relying on 'build' part of the theory, may supply employees with resources to actively explore their environment and conduct actions for intrinsic reasons that fulfill their own inner curiosity [29]. And, based on 'broaden' part of the theory, the enhanced intrinsic motivation is likely to expand individual's momentary thought action repertoires (Ryan \& Deci, 2000), which directly and significantly increases creativity and innovation of employees. Through social contagion process [32], the enhanced creativity at the individual-level may be shared and interacted among members in an organization to promote collective-level innovation.

Figure 1. Theoretical framework

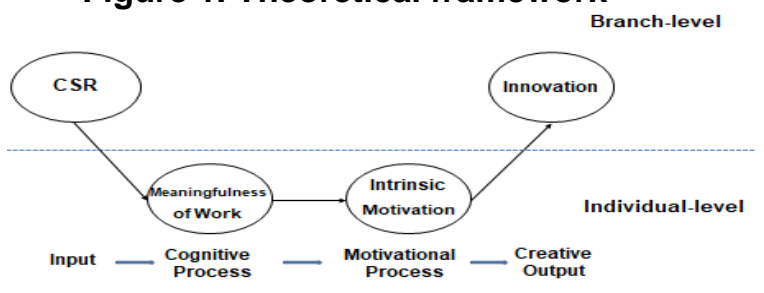

\section{Theories and Hypotheses}

\subsection{CSR and meaning of work}

Human beings have a natural tendency toward meanings [27, 33]. They sincerely seek to understand the purpose of the existence of themselves, others, and life itself. The meaning adopted from the endeavors critically influences the way how they not only interpret various events surrounding them but also determine their responses towards it. Since meaning of life provides direction of life in this way, people are willing to endure the pain which is accompanied in the pursuit of the meaning [27, 33].

Among various domains of life, work context occupies a central position in that work not only provides with resources to make their living but also critically affects an individual's self-actualization. Thus, meaning of work is an important subject that should be addressed to delve into meaning of life [20].

Although meaning of work is an intuitively clear concept to understand, there have been arguments among organizational scholars to define it $[18,20]$. 
They have conceptualized it as a psychological construct -an individual's own perceptions, or sociological construct - shared perceptions or norms influenced by society, or both $[20,27]$. The psychological perspective tends to assume that perceptions of meaning are likely to be originated in individuals' subjective interpretations on his or her work experiences and interactions in an organization [19]. Within this framework, the meaning of work can have various definitions, ranging from general beliefs, values, and attitudes towards their work, to the psychological experience and significance of their work [19, 20]. Meanwhile, a sociological perspective explains that meaning of work reflects socially or culturally affected value systems that members belong to [34]. In other words, the meaning of work is likely to be determined by society rather than being subjectively formed by individual members. In this present study, we consider the meaning of work as a both psychological and sociological construct, emphasizing individual cognitions, feelings, experiences towards their work as well as societal or cultural influences.

What makes people feel meaningfulness in an organization? How does the meaning of work influence their feelings, thoughts, and behaviors in work context? And how can it contribute to organizational outcomes? These questions are fundamental to how members approach, experience, and interpret their work and organization $[18,20,21]$. To answer the questions, many organizational scholars including psychologists, sociologists, and economists have attempted to find antecedents and outcomes of meaning of work [20]. They found that meaning of work is significantly associated with crucial organizational variables, such as organizational identification, job satisfaction, employee engagement, well-being, organizational citizenship behavior, organizational commitment, occupational identification, and job performance [22, 23, 24, 25, 35]. In this paper, we focus on both CSR as an antecedent of meaningfulness of work and innovation as a consequence.

Based on many theoretical suggestions of existing studies [2, 26, 36], we propose that CSR functions as an important driver of employees' meaningfulness of work. Despite many theoretical suggestions on the close association between CSR and meaningfulness of work, to the best of our knowledge, there has been little empirical research examining the relationship. Among various ways to find meaningfulness of work, contributing to society may be very effective to achieve it $[20,26]$. When employees recognize that they make society to be better place through their work, they are likely to feel 'harmony with other people in their society'. This enhanced experience of unity with society may encourage employees to perceive that their work is valuable for themselves as well as their society [20, 26]. Since the philosophy of CSR proposes that firms exist to fulfill the economic and social needs of all stakeholders in the environmental context and ecology rather than only for the profit maximization of shareholders [37], employees who participate in CSR practices are likely to perceive that they are contributing to improvement of their society.

Specifically, the link between CSR and meaningfulness of work can be explained by the psychological and sociological perspectives. According to the psychological viewpoint, participating in CSR practices enables employees to perceive a greater meaningfulness of work by enhancing their self-esteem $[20,25,26]$. By participating in CSR practices, members may perceive that they not only can positively influence others or society but also can substantially make improvement. This enhanced feeling of positive impact would induce them to believe in their ability with confidence, increasing their self-esteem. Then, this sense of competence enables them to discover meaning of work [20, 23, 26]. Moreover, in term of the sociological view, CSR activities can improve meaning of work by encouraging employees to recognize that their work is socially acceptable and valuable [20,34]. CSR activities may enhance members' meaningfulness of work because it corresponds to value systems of modern society, which emphasizes the economic and social needs of shareholders as well as various stakeholders [2]. Therefore, we hypothesize as follows.

Hypothesis 1: CSR increases employee's meaningfulness of work.

\subsection{Meaningfulness of Work and Intrinsic Motivation}

We further propose that employees' belief about social impact and social influence through their work would strengthen their meaningfulness of work; in turn making them experience a strong intrinsic motivation. Thus, an experience of meaningfulness of work may function as a source of intrinsic motivation [20, 30, 38].

Many existing studies have suggested that individual member's meaningfulness of work facilitates their intrinsic motivation. For example, Gagne and his colleagues (1997) empirically proved that meaningfulness of work is significantly associated with intrinsic task motivation [39]. Likewise, Jung and Sosik's (2002) research supported the perspective by showing that individuals who are empowered would experience more intrinsic motivation [40].

Although there have been a number of studies that delves into the relationship, we believe that the extant studies did not fully articulate its theoretical foundation and underlying mechanisms. For this concern, we draw 
upon a broaden-and-build theory of positive emotion [41] to provide an explanation that connects meaningfulness of work with intrinsic motivation. As described above, meaningfulness of work enhances a variety of positive perceptual experiences, such as job satisfaction [25], and engagement [24]. Then, those positive perceptions are likely to increase member's positive emotions $[31,42]$. Therefore, it is expected that meaningfulness of work can enhance positive emotions of members.

According to the broaden-and build theory [41], positive emotions such as joy, interest, contentment, and love, although they seem to be distinct phenomena, are likely to all share the ability to not only broaden individual's momentary thought action repertoires ('broaden' part) but also build their persistent personal resources including physical, intellectual, social, and psychological resources ('build' part). Specifically, the relationship between meaningfulness of work and intrinsic motivation can be explained by 'build' part of the theory. Positive emotions created by experiences of meaningfulness of work can supply psychological "resources" that stimulate individuals to explore new information, experiences, expanding their self in the process [31, 43]. When individuals' physical, intellectual, social, and psychological resources are enhanced by positive emotions, they tend to show exploration, which refers to "explicitly and actively aimed at increasing knowledge of and experience with the target of interest" [29, p. 7]. The positive emotions generate "a feeling of wanting to investigate, become involved, or extend or expand the self by incorporating new information and having new experiences with the person or object that has stimulated the interest" [43, 1977 , p. 216]. Although the positive emotions are not likely to directly induce overt physical actions, those are nonetheless closely related to animated and enlivened feelings [41, 43]. In other words, individuals with the positive emotions may actively explore their environment and conduct actions for intrinsic reasons, which satisfy their own inner curiosity. Therefore, we hypothesize as follows.

Hypothesis 2: Employee's meaningfulness of work increases their intrinsic motivation.

\subsection{Intrinsic Motivation and Innovation}

Scott and Bruce (1994) suggested that research on innovative behavior is fundamentally the investigation of what motivates it, thus motivation should occupy central position of the research agenda [44]. Intrinsic motivation has been regarded as an essential element for members' creativity and innovation [11]. For example, in her conceptualization of creativity, Amabile [46] revealed that intrinsic motivation is one of the most crucial and powerful antecedent of member's creativity [47]. Intrinsically motivated employees tend to transform their motivation into high level of efforts, which then exhibit better task performance requiring creativity and cognitive flexibility [48]. Based on the cognitive advantages being originated in intrinsic motivation, they can search for alternative means to solve problems using non-traditional approaches [47]. In addition, employees who experience intrinsic motivation are likely to persist in their jobs against obstacles [49] as well as concentrate on them better [31]. Their perseverance toward job may function as fuel to overcome various difficulties in the pursuit of creating novel things.

The aforementioned broaden-and-build theory of positive emotion [41] can also be applied to explain the relationship between intrinsic motivation and innovative behavior. Specifically, in this case, we focus on 'broaden' part of the theory to investigate the relationship. Isen and colleagues provided foundational empirical evidences to support that positive emotions broaden individual's momentary thought-action repertoires including (a) cognition, (b) attention, and (c) action [50]. According to Isen's review [50], people who experience positive emotions are likely to express cognitive patterns that are flexible, creative, unusual, open to information, integrative, and efficient. Also, the positive emotions tend to not only increase preference for variety but also make them accept broader behavioral alternatives. In addition, other existing research provided empirical evidences that positive emotions broaden individuals' attentional scope, enabling them to pay attention to both forest and trees, while negative emotions narrow peoples' attention, thus making them miss the view of forest to see the trees. Lastly, previous studies demonstrated that positive affective states facilitate unusual and more various action-repertoires instead of typical, consistent actions, providing preliminary empirical supports for the argument that positive emotions would broaden the scope of action [29, 41]. As described above, we expect that employees with high-level of intrinsic motivation are likely to behave in a creative way.

Moreover, through the social contagion process, the enhanced creativity at the individual-level may be shared and interacted among members in an organization, collectively and upwardly creating collective-level innovation. While creativity is defined as the production of novel and useful ideas by individuals or small groups, organizational innovation is defined as the successful implementation of creative ideas [47]. According to social contagion theory [51], individual members in an organization are likely to be affected by other employees because individual member's cognitions, emotions, and behaviors are not 
only spread over the organization but also interacted among them. The creativity of each individual member who is intrinsically motivated are likely to be interchanged with other member. Through the social interaction processes, individual member's creative ideas can be materialized to implement, being upwardly transformed into collectively-formed innovativeness. Taken the arguments above together, we propose that individual member's intrinsic motivation creates collective-level innovation of the organization.

Hypothesis 3: Employee's intrinsic motivation increases an organizational-level innovation.

\subsection{The Sequential Mediating Role of Meaningfulness of Work and Intrinsic Motivation}

By integrating the aforementioned hypotheses, we propose that employee's meaningfulness of work and intrinsic motivation would sequentially mediate the relationship between CSR and innovation. To incorporate the hypotheses based on theoretical foundation, we draw on group creativity model [16] as an overarching framework. The framework extends the IPO model by addressing specific input and process factors which influence group creativity. According to it, various input factors can be categorized into four dimensions: group member variables (e. g., personality, task relevant knowledge/skill/ability, and attitude toward diversity, and cognitive flexibility), group structure (e. g., diversity, cohesiveness, size, and leadership styles), group climate (e. g., norms of participation, norms for innovation, risk-taking norms, and shared goals/vision), and external demands (e. g., organizational specified goals, organizational structure, task structure, and rewards/penalties). These multidimension input factors can yield creative outputs through cognitive, motivational, and social processes. Cognitive processes are pertinent to generating solutions by attending to others' idea, combining or elaborating on previously generated ideas. Motivational processes indicate the utilizing internal motivators such as intrinsic motivation and external motivators, such as goals and rewards to not only maintain high levels of motivation but also reduce group motivational losses. Social processes mean sharing generated ideas, exchanging information/collaborative problem-solving, discussing varied views, and managing conflict [16].

In other words, given CSR practices can function as important group norms as well as an organizational goal, CSR would be regarded as a critical input factor. And, the input variable may stimulate employees' meaningfulness of work in the form of cognitive processes, in turn facilitating motivational processes by enhancing their intrinsic motivation. Eventually, the increased intrinsic motivation would contribute to boost creativity and innovativeness of the organization. Taken together, employees' meaningfulness of work and intrinsic motivation sequentially mediate the CSRinnovation link. Therefore, we hypothesize as follows.

Hypothesis 4: Employee's meaningfulness of work and intrinsic motivation sequentially mediate the relationship between CSR and innovation.

\section{Method}

\subsection{Research Design}

We empirically examine the theoretical hypotheses with a 3 -wave longitudinal research design. We sample 4,178 employees of 502 branches from one of the largest Korean commercial banks. We match a branch-level information for CSR and innovation (level 2) with an employee-level meaningfulness of work and intrinsic motivation (level 1). With the dataset, a multilevel mediation model is tested.

We believe that our branch-level approach provides an adequate research setting context to test our hypotheses for the following reasons. First of all, each branch has an independent institutional structure which implements CSR activities and innovation in its own way, which allows enough variance of CSR and innovation across branches, even though branches are nested within one bank. In addition, because whole branches are faced with similar business environments that can implicitly affect CSR and innovation (i.e., a variety of corporate strategies, a technological level, the degree of new technology adoption, and industrial growth rate), our branch-level approach is beneficial to control various environmental factors.

We gathered the data from two independent sources which consist of (a) surveys of members, and (b) archival data from the bank's official records. The surveys data from branch members included measures of meaningfulness of work, intrinsic motivation, and innovation. CSR was collected from the official archival records. By collecting data from different sources, we could diminish the possibility of common method variance (CMV) problem [52].

We gathered our data at three different time points. Time 2 was apart from Time 1 by a lag of 8 months, and Time 3 was also separated from Time 2 by a lag of 12 months. The time intervals also would decrease the likelihood of potential problem of CMV. Although we believe that we considered adequate time lags (several months) to investigate relationships among the research variables over time, the processes of the survey was mainly determined by the availability of participant bank. 
At Time 2, we gathered data from 6473 members of 707 branches, and 6414 members of 627 branches included in our survey at Time 3 . We eliminated all missing data and selected branches for which at least three participants adequately responded to the survey. In addition, we selected branches that were available in all three time points-Time 1,2, and 3-and provided all related survey data including various control variables. As a result, in final analysis, 4,178 employees of 502 branches remained including all research variables as well as all time points.

\subsection{Measures}

All research variables were measured by multi-item scales with a five-point Likert scale $(1=$ strongly disagree, 5 = strongly agree). To analyze our research model at branch-level, we converted the result of individual-level survey into branch-level by aggregating the individual data-computing the mean value of innovation per branch-thus creating branch- level innovation variables. Then we calculated internal consistency of all variables using Cronbach alpha coefficients at the branch-level.

CSR. Grounded on existing literature on CSR measures, at time 1 , we extracted the major components of CSR scales such as social, customer, and employee dimension from the archival records of the branch's KPI. Social dimension includes the degree of implementation on various kinds of public campaigns for society (e.g., "Accompanying with Warmth Campaign”). Customer dimension means the degree of operating various consumer protection systems such as "consumer protection programs and department". And employee dimension consists of the degree of operating training \& development systems. To composite the CSR measure, we not only utilized the logarithm of the each dimension but also weighted each dimension by the same percentage.

In terms of the variance of CSR across branches, the mean value of branch-level CSR is 5395.67, and standard deviation across branches is 317.67 . This indicates that CSR activities which are implemented by each branch can be differentiated, having adequate independent variance.

Meaning of work. At time 2, to assess meaning of work, we selected and combined 5 items from measures which used extant studies [22, 25] for the purpose of this research. Typical items included in our study are: (a) "The work that I do is meaningful"; (b) "The work that I do makes the world a better place"; (c) "My work is one of the most important things in my life," (d) "I would choose my current work life again if I had the opportunity"; (e) If I was financially secure, I would continue with my current line of work even if I was no longer paid". We choose the 5 items because they comprehensively capture core factors of meaning of work as used in the previous studies $[22,25]$. The value of Cronbach alpha in this study was $=.85$.

Intrinsic motivation. To measure intrinsic motivation at time point 2 , we selected and modified 3 items from 4 items of Guay and his colleagues for the purpose of this research [53]. The items included in our study are: (a) I am currently engaged my work because I think that this activity is interesting"; (b) "I feel good when doing this activity"; (c) "I enjoy talking about my work to others". The 3 items include key factors of the scale, excluding redundant item. The value of Cronbach alpha in this research was $=.85$.

Innovation. We utilized 3 items which is adapted from extant research [54]. Sample items are "Our company always searches for novel solutions, considering the implementation of those", "Our company develops and implements innovative ideas with available supports for innovation". (Cronbach alpha $=.93$ ).

Control Variables. To minimize biased estimates, we controlled various factors for innovation. All control variables were converted to the average value of each branch. Based on existing research [55], we included group size and employees' tenure.

\subsection{Aggregation procedures}

We delved into whether the aggregation is valid by utilizing various criteria such as $r_{\mathrm{wg}(\mathrm{J})}$, and the intraclass correlation coefficients-ICC(1) and ICC(2). First, we calculated the $r_{\mathrm{wg}(\mathrm{J})}$ values of the individual-level research variables and then converted to averaged value of each branch. According to the extant study [56], an $r_{\mathrm{wg}(\mathrm{J})}$ of .70 is regarded as a sufficient value to justify aggregation. Average $r_{\mathrm{wg}(\mathrm{J})}$ value of innovation was .68, demonstrating acceptable within-group agreement to aggregate the individual-level variables to the branchlevel of analysis. Next, we calculated ICC(1) for our research variables. By averaging the between-branch and within-branch variance components for the variables, we calculated the average ICC(1). The ICC(1) of innovation was greater than $.12(.42)$, the criteria value of ICC(1) used in the previous organizational literature (James, 1982). Then, to evaluate the reliability of the branch-level means, we calculated ICC(2) values for all our research variable. The $\operatorname{ICC}(2)$ value of innovation was .67, which was greater than .60, the recommended ICC(2) score (Glick, 1985). In all, the results of $r_{\mathrm{wg}(\mathrm{J})}$, ICC(1), and $\mathrm{ICC}(2)$ revealed that the aggregation of our individual-level variables into the branch-level is valid.

\subsection{Statistical Analysis}


We conducted a correlation analysis to gain a basic insight into our data. Then we assessed the fit indices of our hypothesized mediation model using multilevel structural equation modeling (MSEM). We used a multi-level model with CSR and innovation at the level 2 and employees' meaningfulness of work and intrinsic motivation at the level 1. The MSEM is an optimal tool to test complex models, such as multilevel mediation analysis [57]. It can verify latent variables with multiple indicators, adequately controlling for measurement errors. Thus, MSEM is useful to deal with the issue of underestimating multilevel mediation effects. In our research, we took a two-step approach consisting of measurement model and structural model tests according to the suggestion of Anderson and Gerbing [58]. First, a confirmatory factor analysis was conducted to analyze the measurement model. Second, we tested a structural, hypothesized relationship among research variables using MSEM. MSEM can consider the fact that members are nested within their groups, thus researcher should assume that they are not independent. The analytical processes of MSEM have in common with those of hierarchical linear modeling, except for adding information about various model fit indices. We conducted the analyses using the M-plus 7 package [59].

A model fit was assessed by a variety of goodnessof-fit indices, such as a chi-square $\left(\chi^{2}\right)$, comparative fit index (CFI), Tucker-Lewis index (TLI), and root mean square error of approximation (RMSEA) that are commonly recommended in the existing studies [60]. Desirable model fit is related to a CFI and TLI greater than .90, and a RMSEA less than or equal to .06. In addition, we compared our hypothesized model to a nested alternative model to find best model which fits the data through chi-square difference test. The fit of the structural models was evaluated by goodness-of-fit indices such as $\chi^{2}$, CFI, TLI, and RMSEA.

Table 1. Correlations

\begin{tabular}{|c|c|c|c|c|c|}
\hline Variable & 1 & 2 & 3 & 4 & 5 \\
\hline 1. CSR & - & & & & \\
\hline $\begin{array}{l}\text { 2. Meaning of } \\
\text { work }\end{array}$ & $.11^{* *}$ & - & & & \\
\hline $\begin{array}{l}\text { 3. Intrinsic } \\
\text { motivation }\end{array}$ & $.07 * *$ & $.85 * *$ & - & & \\
\hline 4. Innovation & $.09 * *$ & $.14 * *$ & $.13 * *$ & - & \\
\hline 5. Team Size & $-.37 * *$ & $-.05 * *$ & -.02 & -.04 & - \\
\hline $\begin{array}{l}\text { 6. Tenure } \\
\text { (month) }\end{array}$ & $.09 * *$ & $.15 * *$ & $.10 * *$ & .02 & $-.13 * *$ \\
\hline
\end{tabular}

\section{Results}

The correlation analysis below was performed to examine the relationships among the research variables.

\subsection{Measurement Model}

To test a measurement model, we performed multilevel confirmatory factor analyses (MCFA) to examine whether the measurement model exhibited an acceptable fit to the data. To identify discriminant validity of our three latent variables (i.e., meaningfulness of work, intrinsic motivation, and innovation), MCFA of all 11 items that compose all scales was conducted. Although the value of RMSEA was not good, the three-factor model demonstrated an overall acceptable fit to the observed data $\left(\chi^{2}=1525.14\right.$; $d f=51 ; \mathrm{CFI}=.940 ; \mathrm{TLI}=.902$, and RMSEA $=.083)$. We sequentially compared the three-factor model to twofactor and single-factor models, conducting chi-square difference tests. The results of the chi-square difference tests demonstrated that the three-factor model fits the data better than any of the other alternative models, suggesting the discriminant validity of our focal variables.

\subsection{Structural Model}

Based on the above correlation analysis, we established a multi-level structural equation model that comprehensively explains the relationship among our study variables. The model includes both a multilevel mediating structure that leads to CSR $\rightarrow$ meaningfulness of work $\rightarrow$ intrinsic motivation $\rightarrow$ innovation. In order to test the model, we conducted a multi-level mediation model analysis.

To analyze the multilevel mediating effects of meaningfulness of work and intrinsic motivation, we applied Preacher et al.'s [57] model (MSEM). Multiple indicators were used to measure the latent variables of CSR and innovation (Level 2), and meaningfulness of work and intrinsic motivation (Level 1). Then, Path A (CSR $\rightarrow$ meaningfulness of work) and Path B (meaningfulness of work $\rightarrow$ intrinsic motivation), and Path C (intrinsic motivation $\rightarrow$ innovation) were estimated simultaneously. When a model involves the downward and upward effects (e.g., 2-1-1-2 model), the mediation effect is inherently analyzed at the betweengroup level [57].

Before analyzing the 2-1-1-2 model, we conducted a model comparison test. To find a best model that fits to the data, we compared fit indices between the hypothetical model and alternative nested model, conducting chi-square difference test. First, we tested our hypothesized full mediation model (Model 1) using MSEM. The fit indices of the full mediation model were good enough to accept. Next, we compared Model 1 
with an alternative nested model, partial mediation model (Model 2). Model 2 is identical to Model 1 with the exception of the addition of one path (the path from CSR to innovation). The result of chi-square difference test demonstrated that the fit of Model 1 was much better than Model $2\left(\Delta \chi^{2}[1]=-545.17, p<.001\right)$. The results indicate that the full mediation model has the best fit, ruling out the partial mediation mechanism. The result means that our hypothesis 4 was supported.

As shown in Figure 2, CSR was directly and positively related to meaningfulness of work $(\gamma=0.47, p$ $<.001 ; 90 \% \mathrm{CI}, 0.28,0.65)$. Also meaningfulness of work was positively related to intrinsic motivation $(\gamma=$ $0.93, p<.001 ; 90 \% \mathrm{CI}, 0.84,1.03)$, and intrinsic motivation was positively associated with innovation $(\gamma$ $=0.87, p<.001 ; 90 \%$ CI, 0.54, 1.19). This MSEM approach provided fit indices for the indirect effect of innovation, and these indices showed an adequate model fit $\left(\chi^{2}=2119.694, d f=92\right.$, CFI $=0.927$, TLI $=0.902$, and RMSEA =0.073). Hence, Hypothesis 1, 2, and 3 were supported.

To test the sequential mediation effect of meaningfulness of work and intrinsic motivation between CSR and innovation, we calculated the indirect effect of CSR on innovation through the sequential mediators. Previous research [61] highly recommended the $95 \%$ confidence interval (CI) for the mean indirect effect. When the CI does not include zero, the indirect effect is statistically significant at the .05 level. The CI for the mean indirect effect of CSR on innovation through meaningfulness of work and intrinsic motivation do not include zero $(95 \% \mathrm{CI}=[1.06,3.60])$. The result means that the mediation effect between CSR and innovation was statistically significant, thus confirming Hypothesis 4.

\section{Figure 2. Final result}

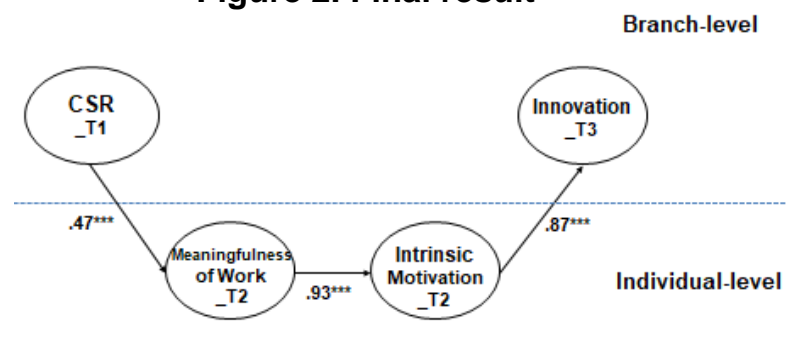

\section{Discussion}

In the present research, based on group creativity model [16], we attempt to untangle the complex mechanism by which CSR promotes an organizational innovation. To this end, we utilize a 3 -wave longitudinal survey data and archival data from 4,178 employees of 502 branches in a Korean large bank. By analyzing mediation model utilizing MSEM technique, we examine the underlying process that intermediates the relationship between CSR and innovation. The results demonstrate that employees' meaningfulness of work and intrinsic motivation serve as the sequential mediators between CSR and innovation.

We claim that our research contributes to existing literature on CSR and innovation theoretically and methodologically. First, by unveiling the internal intermediating mechanism between CSR and innovation, we integrate CSR research with innovation literature to complement the externally-oriented perspective of existing CSR research stream. Although many existing studies on CSR have revealed the association between CSR and various organizational outcomes, the possibility that CSR affects innovation has been relatively underexplored. Given that innovation is critical to maintain competitive advantage as well as survival in today's relentless competition, our attempt to investigate the role of CSR as a critical driver of innovation is timely and meaningful. In addition, by testing the micro-level underlying mechanisms of the macro-level hypothesized linkage, this study showcases how the relationship between macro-level variables (i.e., CSR and organizational innovation) can be explained by micro-level mediators (i.e., employees' meaningfulness of work and intrinsic motivation). Relying on group creativity framework [16], we try to integrate the macroand micro-approach into a single comprehensive model under the overarching theory.

Second, this research relates meaningfulness of work research to both CSR and innovation literature. Our results show that an employee's sense of meaningfulness of work translates CSR into a cognitive process that triggers intrinsic motivation, eventually facilitating their creativity and innovation. Although many previous studies $[2,14,26,28,36]$ have proposed the relationship between CSR and meaningfulness of work, this study is the first one that attempts to test the hypotheses empirically.

Lastly, our research also provides some methodological contributions. The majority of existing studies on CSR have relied a single-level and crosssectional research designs. However, this study tries to capture the reality more accurately by taking a multilevel approach within a longitudinal setup [2, 14].

The results of this research may provide some meaningful practical implications. First, our results would provide top managers with insight on the critical role of CSR practices as an effective tool to boost innovation. Although many scholars have demonstrated the strategic importance of CSR which enhances organizational outcomes, some leaders tend to consider it as merely cost or tax-like obligation that firms should conform. However, if employees experience a sense of meaningfulness and value of their work through CSR 
activities, they will feel more intrinsic motivation, then in turn being more creative. Considering the fact that the employee' perceptions and work attitudes toward their job have a huge impact on the organizational outcomes, the attempt to improve their perceptions and attitudes through CSR is a reasonable choice being worth of investment.

Second, the results that employees' meaningfulness of work and intrinsic motivation sequentially mediate the relationship between CSR and innovation may provide valuable information to confirm whether the CSR practices actually influence employees' perceptions and attitudes. By carefully observing the level of perceived meaningfulness of work and intrinsic motivation, organizational managers can identify whether CSR's positive effects on employees exists. In other words, the extent to which employees perceive both the meaningfulness of work and intrinsic motivation indicates the effectiveness of CSR implementation. To the contrary, if employees do not perceive meaningfulness of work despite of endeavors to implement CSR practices, CSR practices are said to work less effectively in the organization.

Despite the contributions and implications, this research is not without limitations. First, although the principles of CSR would be a universal value across the globe, there can be cultural implications for an employee's perception of CSR. As such, since we only collected data from a Korean firm, we cannot exclude the possibility of cultural impacts. Therefore, we interpret and apply our results into different cultures with a great caution.

Second, our research considers only one commercial bank. Thus, it would not be appropriate to generalize the results to other industrial contexts. In addition, because all respondents who participated in this study belong to the same industry, we could not control the influences of external factors such as industrial or environmental impacts.

Lastly, the survey used in this research was based on self-report by organizational members. Since selfreporting can be different from their actual behaviors, it is recommended to collect additional data such as a third party's observation or reports by other colleagues.

Despite all of the limitations, we believe that our research contributes to CSR literature substantially from theoretical and methodological standpoint. It deepens the understanding of micro-foundations of CSR by revealing the underlying mechanisms through which CSR affects innovation. Our findings conclude that CSR would pay off with a form of innovation through a positive change in employees' cognition and motivation toward their jobs.

\section{References}

[1] Carroll, A. B. 1979. "A three-dimensional conceptual model of corporate social performance", Academy of Management Review, 4, 1979, pp. 497-505.

[2] Aguinis, H., and Glavas, A. "What we know and don't know about corporate social responsibility: a review and research agenda", Journal of management, 38, 2012, pp. 932-968.

[3] Porter, M. E., and Kramer, M. R.. "Strategy and society: The link between competitive advantage and corporate social responsibility", Harvard Business Review, 85, 2007, pp. 78-92.

[4] Brammer, S. J., and Pavelin, S. "Corporate reputation and social performance: The importance of fit", Journal of Management Studies, 43, 2006, pp. 435-455.

[5] Sen, S., and Bhattacharya, C. B. "Does doing good always lead to doing better? Consumer reactions to corporate social responsibility", Journal of Marketing Research, 38, 2001, pp. 225243.

[6] Brammer, S., and Millington, A. "Does it pay to be different? An analysis of the relationship between corporate social and financial performance", Strategic Management Journal, 29, 2008, pp. 1325-1343.

[7] Doh, J. P., Howton, S. D., Howton, S. W., and Siegel, D. S. "Does the market respond to endorsement of social responsibility? The role of institutions, information, and legitimacy", Journal of Management, 36, 2010, pp. 1461-1485.

[8] Graves, S. B., and Waddock, S. A. "Institutional owners and corporate social performance", Academy of Management Journal, 37, 1994, pp. 1034-1046.

[9] Farooq, O., Payaud, M., Merunka, D., and Valette-Florence, P. "The impact of corporate social responsibility on organizational commitment: Exploring multiple mediation mechanisms", Journal of Business Ethics, 125, 2014, pp. 563-580.

[10] Amabile, T. M., Conti, R., Coon, H., Lazenby, J., and Herron, M. "Assessing the work environment for creativity", Academy of management journal, 39, 1996, pp. 1154-1184.

[11] Woodman, R.W., Sawyer, J. E., and Griffin, R.W. "Toward a theory of organizational creativity", Academy of Management Review, 18, 1993, pp. 293-321.

[12] Glavas, A., and Piderit, S. K. "How does doing good matter? Effects of corporate citizenship on employees" Journal of Corporate Citizenship, 36, 2009, pp. 51-70.

[13] Oldham, G. R., and Cummings, A. "Employee creativity: Personal and contextual factors at work", Academy of management journal, 39, 1996, pp. 607-634.

[14] Rupp, D. E. and Mallory, D. B. "Corporate social responsibility: Psychological, person-centric, and progressing", Annual Review of Organizational Psychology and Organizational Behavior, 2, 2015, pp. 211-236.

[15] Chang, Y. K., Oh, W. Y., and Messersmith, J. "Translating corporate social performance into financial performance: Exploring the moderating role of high-performance work practices", International Journal of Human Resource Management, 24, 2013, pp. 3738-3756.

[16] Paulus, P. B., and Dzindolet, M. "Social influence, creativity and innovation", Social Influence, 3, 2008, pp. 228-247.

[17] Kim, M., and Shin, Y. "Collective efficacy as a mediator between cooperative group norms and group positive affect and team creativity", Asia Pacific Journal of Management, 32, 2015, pp. 693-716.

[18] Nord, W. R., Brief, A. P., Atieh, J. M., and Doherty, E. M. "Studying meanings of work: The case of work values", Lexington Books/DC Heath and Com. 1990.

[19] Wrzesniewski, A., Dutton, J. E., and Debebe, G. "Interpersonal sensemaking and the meaning of work", In Kramer, R. M., and Staw, B. M (Eds), Research in Organizational Behavior, 25, 2003, pp. 93-135. 
[20] Rosso, B. D., Dekas, K. H., and Wrzesniewski, A. "On the meaning of work: A theoretical integration and review", Research in Organizational Behavior, 30, 2010, pp. 91-127.

[21] Wrzesniewski, A., and Dutton, J. E. "Crafting a job: Revisioning employees as active crafters of their work", Academy of Management Review, 26, 2001, pp. 179-201.

[22] Bunderson, J. S., and Thompson, J. A. "The call of the wild: Zookeepers, callings, and the double-edged sword of deeply meaningful work", Administrative science quarterly, 54, 2009, pp. 32-57.

[23] Cardador, M. T., Dane, E., and Pratt, M. G. "Linking calling orientations to organizational attachment via organizational instrumentality", Journal of Vocational Behavior, 79, 2011, pp. 367-378.

[24] May, D. R., Gilson, R. L., and Harter, L. M. "The psychological conditions of meaningfulness, safety and availability and the engagement of the human spirit at work", Journal of occupational and organizational psychology, 77, 2004, pp. 11-37.

[25] Wrzesniewski, A., McCauley, C., Rozin, P., and Schwartz, B. "Jobs, careers, and callings: people's relations to their work", Journal of Research in Personality, 31, 1997, pp. 21-33.

[26] Bauman, C. W., and Skitka, L. J. "Corporate social responsibility as a source of employee satisfaction". Research in Organizational Behavior, 32, 2012, pp. 63-86.

[27] Baumeister, R. F., and Vohs, K. D. "The pursuit of meaningfulness in life", In C. R. Snyder and S. J. Lopez (Eds.), The handbook of positive psychology, pp. 608-618. New York: Oxford University Press. 2002.

[28] Aguinis, H., and Glavas, A. "On Corporate Social Responsibility, Sensemaking, and the Search for Meaningfulness Through Work", Journal of Management, 0149206317691575, 2017.

[29] Fredrickson, B. L. "The role of positive emotions in positive psychology", American Psychologist, 56, 2001, pp. 218-226.

[30] Oldham, G. R., Hackman, J. R., and Pearce, J. L. "Conditions under which employees respond positively to enriched work", Journal of Applied Psychology, 61, 1976, pp. 395.

[31] Ryan, R. M., and Deci, E. L. "Self-determination theory and the facilitation of intrinsic motivation, social development, and well-being", American psychologist, 55, 2000, pp. 68.

[32] Pfeffer, J. "Organization theory and structural perspectives on management", Journal of Management, 17, 1991, pp. 789-803. [33] Frankl, V. E. Man's search for meaning. Boston: Beacon Press. 1959.

[34] Kluckhohn, F. R., and Strodtbeck, F. L. (1961). Variations in value orientations.

[35] Liden, R. C., Wayne, S. J., and Sparrowe, R. T. "An examination of the mediating role of psychological empowerment on the relations between the job, interpersonal relationships, and work outcomes", Journal of applied psychology, 85, 2000, pp. 407. [36] Michaelson, C., Pratt, M. G., Grant, A. M., and Dunn, C. P. "Meaningful work: Connecting business ethics and organization studies", Journal of Business Ethics, 121, 2014, pp. 77-90.

[37] McWilliams, A., and Siegel, D. "Corporate social responsibility: A theory of the firm perspective", Academy of management review, 26, 2001, pp. 117-127.

[38] Thomas, K. W., and Velthouse, B. A. "Cognitive elements of empowerment: An "interpretive" model of intrinsic task motivation", Academy of management review, 15, 1990, pp. 666681.

[39] Gagné, M., Senecal, C. B., and Koestner, R. "Proximal job characteristics, feelings of empowerment, and intrinsic motivation: A multidimensional model", Journal of applied social psychology,
27, 1997. pp. 1222-1240.

[40] Jung, D. I., and Sosik, J. J. "Transformational leadership in work groups: The role of empowerment, cohesiveness, and collective-efficacy on perceived group performance", Small group research, 33, 2002, pp. 313-336.

[41] Fredrickson, B. L. "What good are positive emotions?", Review of General Psychology, 2, 1998, pp. 300-319.

[42] Lazarus, R. S. "Progress on a cognitive-motivationalrelational theory of emotion", American psychologist, 46, 1991, pp. 819.

[43] Izard, Carroll E. Human Emotions. New York: Plenum Press. 1977.

[44] Scott, S. G., and Bruce, R. A. "Determinants of innovative behavior: A path model of individual innovation in the workplace", Academy of Management Journal, 37, 1994, pp. 580-607.

[46] Amabile, T. M. "The social psychology of creativity: A componential conceptualization", Journal of personality and social psychology, 45, 1983, pp. 357.

[47]Amabile, T. Creativity in context. Westview press. 1996.

[48]Kehr, H. M. "Integrating implicit motives, explicit motives, and perceived abilities: The compensatory model of work motivation and volition", Academy of management review, 29, 2004, pp. 479-499.

[49] Parker, S. K., Williams, H. M., and Turner, N. "Modeling the antecedents of proactive behavior at work", Journal of applied psychology, 91, 2006, pp. 636.

[50] Isen, A. M. "Positive Affect and Decision Making", In Michael Lewis and Jeannette M. Haviland, eds., Handbook of Emotions (2nd ed.), New York: The Guilford Press. 2000.

[51] Burt, R. S. "Social contagion and innovation: Cohesion versus structural equivalence", American Journal of Sociology, 1987, pp. 1287-1335.

[52] Podsakoff, P. M., MacKenzie, S. B., Lee, J. Y., and Podsakoff, N. P. "Common method biases in behavioral research: a critical review of the literature and recommended remedies", Journal of applied psychology, 88, 2003, pp. 879 .

[53] Guay, F., Vallerand, R.J., and Blanchard, C. "On the assessment of situational intrinsic and extrinsic motivation: The Situational Motivation Scale (SIMS)", Motivation and Emotion, 24, 2000, pp. 175-213.

[54] Siegel, S. M., and Kaemmerer, W. F. "Measuring the perceived support for innovation in organizations", Journal of Applied Psychology, 63, 1978, pp. 553-562.

[55] Hülsheger, U. R., Anderson, N., and Salgado, J. F. "Teamlevel predictors of innovation at work: a comprehensive metaanalysis spanning three decades of research", Journal of Applied psychology, 94, 2009, pp. 1128.

[56] James, L. R., Demaree, R. G., and Wolf, G. "Estimating within-group interrater reliability with and without response bias", Journal of Applied Psychology, 69, 1984, pp. 85-98. [57] Preacher, K. J., Zyphur, M. J., Zhang, Z. “A general multilevel SEM framework for assessing multilevel mediation", Psychological Methods, 15, 2010, pp. 209-233.

[58] Anderson, J. C., and Gerbing, D. W. "Structural equation modeling in practice: A review and recommended two-step approach", Psychological Bulletin, 103, 1988, pp. 411-423. [59]Muthen, L. K., and Muthen, B. O. Mplus user's guide (7th ed.). Los Angeles, CA: Muthen and Muthen. 2015.

[60] Hu, L., and Bentler, P. M. "Cutoff criteria for fit indexes in covariance structure analysis: Conventional criteria versus new alternatives", Structural Equation Modeling, 6, 1999, pp. 1-55. [61] Shrout, P. E., and Bolger, N. "Mediation in experimental and nonexperimental studies: New procedures and recommendations", Psychological Methods, 7, 2002, pp. 422. 